\title{
Comparison of the cytotoxic effects and smear layer removing capacity of oxidative potential water, $\mathrm{NaOCl}$ and EDTA
}

\author{
Ahmet Serper ${ }^{\S}$, Semra Çalt ${ }^{\S}$, A. Lale Dogan ${ }^{\dagger}$, Dicle Guc ${ }^{\dagger}$, Bahar Özçelik ${ }^{\S}$ and \\ Tulin Kuraner ${ }^{\S}$ \\ ${ }^{\S}$ Department of Endodontics, Faculty of Dentistry, Hacettepe University, Ankara, Turkey \\ ${ }^{\dagger}$ Department of Basic Oncology, Oncology Institute, Hacettepe University, Ankara, Turkey
}

(Received 24 February and accepted 9 October 2001)

\begin{abstract}
This study compared the smear layer removing capability and cytotoxicity of $\mathrm{NaOCl}$, EDTA and Oxidative Potential Water (OPW). Fifteen extracted single-rooted human upper incisors were examined in three groups. The root canals were enlarged to the apical foramen with $K$ files to size \#60 and irrigated with: (a) NaOCl followed by OPW, (b) OPW during and after instrumentation and (c) $\mathrm{NaOCl}$ followed by EDTA and $\mathrm{NaOCl}$. The effect of these irrigants on the smear layer was evaluated using a scanning electron microscope. In vitro cytotoxicity of these irrigants was examined by MTT colorimetric assay. We found that the combination of $\mathrm{NaOCl}$ and $\mathrm{OPW}$ as well as the application of OPW alone, failed to remove the smear layer from the apical third, whereas the EDTA and $\mathrm{NaOCl}$ combination achived complete removal. OPW, when used during and after instrumentation, removed the smear layer in the middle third more effectively than NaOCI followed by OPW. EDTA exerted more cytotoxic effects at all concentrations tested when compared with OPW and NaOCl. In conclusion: (a) OPW was less cytotoxic than other irrigants but did not effectively remove the smear layer, (b) treatment with EDTA followed by $\mathrm{NaOCl}$ efficiently removed of the smear layer, but their cytotoxicity should be considered during endodontic therapy. (J. Oral Sci. 43, 233-238, 2001)
\end{abstract}

Correspondence to Dr. Ahmet Serper, Department of Endodontics, Faculty of Dentistry, Hacettepe University, Sihhiye (06100), Ankara, Turkey

Tel: + 90-312-305-22-60

Fax: + 90-312-309-28-32

E-mail address: aserper@hacettepe.edu.tr
Key words: irrigation solution; smear layer; cytotoxicity.

\section{Introduction}

Irrigation solutions have been used in endodontics for removing necrotic tissues, smear layer, bacteria and debris from the root canal $(1,2)$. Although numerous studies have been done in vitro, the relative effectiveness of different irrigants has not been clearly demonstrated in clinical usage (3).

Sodium hypochlorite $(\mathrm{NaOCl})$ is widely used as an irrigation solution because of its tissue dissolving, lubricant and also antibacterial properties (1-5). In order to obtain acceptable bactericidal and solvent effects, $5.25 \% \mathrm{NaOCl}$ solution has been recommended (2). However, effective concentrations of this solution are reported to be cytotoxic $(6,7)$. The cytotoxicity of $\mathrm{NaOCl}$ is reduced at lower concentrations, but dilution impairs its irrigant properties $(2,5,8)$. It is generally agreed that there is no single solution which has the ability to remove both organic and inorganic components of the smear layer. Therefore, it was recommended that the most effective procedure to adequately clean the root canal system is to irrigate the canals with ethylenediaminetetraacetic acid (EDTA) followed by $\mathrm{NaOCl}$ (9-11).

Recently, Hata et al. (12) studied a new antibacterial and antiviral agent for root canal irrigation, Oxidative Potential Water (OPW), which was developed in Japan for disinfecting purposes. In their study, OPW was reported to be effective in removing the smear layer. With the absence of any toxicity, and with its antimicrobial properties and smear layer removal capability, OPW seems to be an 
acceptable endodontic irrigation solution.

The purpose of this study was to investigate the potential of OPW as an irrigation solution for endodontic treatment. The questions to be tested was whether the OPW was an acceptable endodontic irrigation solution regarding cytotoxicity and efficacy in smear layer removal, and whether it can be an alternative to $\mathrm{NaOCl}$ and EDTA.

\section{Materials and Methods}

Scanning electron microscopic (SEM) examination

Fifteen extracted single-rooted human upper incisors were used in this study. Following extraction, the teeth were stored in a physiological saline solution at $37^{\circ} \mathrm{C}$ for $48 \mathrm{~h}$. The access cavities were then prepared and the working length was established. The teeth were randomly divided into three groups and the root canals were enlarged to the apical foramen with $\mathrm{K}$ files to size \#60 by using the stepback technique, producing a standard flare by the insertion of \#3-5 Gates Glidden drills. The specimens were irrigated as follows: Group 1: $2 \mathrm{ml}$ of $5 \% \mathrm{NaOCl}$ (ACE, Procter \& Gamble, Istanbul, Turkey) was used between each instrument size and the final irrigation was accomplished with $10 \mathrm{ml}$ of OPW (NDX-250KH, Nihon Aqua Co. Ltd., Kyoto, Japan) for $2 \mathrm{~min}$.

Group 2: $2 \mathrm{ml}$ of OPW was used between each instrumentation, and $10 \mathrm{ml}$ of OPW was used for $2 \mathrm{~min}$ as the final flush.

Group 3: $2 \mathrm{ml}$ of 5\% $\mathrm{NaOCl}$ was used between each instrumentation and then the canals were flushed with 10 $\mathrm{ml}$ of $17 \%$ EDTA (Sigma Chemical Co., St. Louis, MO) for $2 \mathrm{~min}$ followed by $10 \mathrm{ml}$ of $5 \% \mathrm{NaOCl}$.

The crowns of the teeth were removed with a highspeed handpiece with a water spray at the cementoenamel junction. All the roots were then sectioned longitudinally. These root samples were fixed with $2.5 \%$ phosphatebuffered gluteraldehyde at $4^{\circ} \mathrm{C}$ for 9 days. After fixation, samples were washed with phosphate buffer and dehydrated with increasing concentrations of acetone $(25,50,75$, $100 \%)$. Dehydration was completed with a critical point dryer. Samples were coated with $200 \AA$-thick gold using a gold- coating apparatus and examined for SEM (JEOLSEM 6400) evaluation.

\section{Cytotoxicity test}

Cell Cultures. L929 mouse fibroblasts (ATCC) were cultured in $25 \mathrm{~cm}^{2}$ culture flasks containing RPMI-1640 supplemented with $10 \%$ fetal bovine serum, $2 \mathrm{mM} \mathrm{L-}$ glutamine (Sigma Chemical Co., St. Louis, MO), 100 $\mu \mathrm{g} / \mathrm{ml}$ of streptomycin, $100 \mu \mathrm{mg} / \mathrm{ml}$ of penicillin (Sebak, Biologische Fordchungs $\mathrm{GmbH}$, Germany) at $37^{\circ} \mathrm{C}$ in a humidified incubator under an ambient air pressure atmosphere containing $5 \% \mathrm{CO}_{2}$. Confluent cell monolayers were trypsinized; after the fourth passage, cells were used in the cytotoxicity experiments as described below. The irrigation solutions were filtered through a $0.2 \mu \mathrm{m}$ filter (Minisart NML, Sartorious $\mathrm{GmbH}$, Germany). Various dilutions (final dilution: 1/2,1/4,1/8 and 1/16) were prepared in order to use in the cytotoxicity assay.

MTT Assay. A simple colorimetric assay developed by Mosmann (13) as a test for cell proliferation and survival was adapted for the measurement of cytotoxicity. This assay involves the ability of viable cells to convert a soluble tetrazolium salt, MTT [3-(4,5- dimethylthiazol-2-yl)-2,5diphenyltetrazolium bromide], into a blue formazan endproduct by mitochondrial dehydrogenase enzymes. The blue color reaction is used as a measure of the cell viability. The assay is performed in 96-well plates and results are read on a multiwell spectrophotometer. A modified method of the colorimetric MTT assay was used in this study (14). For this purpose, $2 \times 10^{4}$ cells in $50 \mu \mathrm{l}$ of culture medium were seeded in flat-bottomed microplates (Costar, Cambridge, MA) and $50 \mu 1$ of sterile irrigation solution was added to each well. Cells in $50 \mu \mathrm{l}$ of culture medium alone served as a control for the cell viability. The assay was run in quadruplicate so that control and dilution values were obtained as the mean values of four identical wells.

After a $24 \mathrm{~h}$ incubation at $37^{\circ} \mathrm{C}$ under a humidified, $5 \%$ $\mathrm{CO}_{2}$-containing air atmosphere, $25 \mu \mathrm{l}$ of $5 \mathrm{mg} / \mathrm{ml}$ MTT (Sigma Chemical Co., St. Louis, MO) in saline was added into each well and incubated for a further $3 \mathrm{~h}$ at $37^{\circ} \mathrm{C}$. A solubilization buffer consisting of $23 \%$ sodium doedcyl sulphate (SDS; Sigma Chemical Co., St. Louis, MO) in $50 \%$ N,N dimethylformamide ( $\mathrm{pH} 4.7$ ) was used to dissolve the formazan precipitate. For this purpose, $80 \mu \mathrm{l}$ of solubilization buffer was added into each well and plates were then incubated overnight at $37^{\circ} \mathrm{C}$. The optical densities (OD) of the plates were read by a microplate spectrophotometer (Coulter, Electronics, Inc., Hialeah, FL) at $570 \mathrm{~nm}$.

Analysis of cytotoxicity. Analysis of the potential cytotoxicity of the irrigation solutions under investigation was conducted as follows. First, the optical densitometric readings of each of the four wells were determined and the arithmetic mean \pm standard error of these four recordings were calculated. Second, an arbitrary unit of 100 was assigned to the optical densitometric reading obtained from the control wells. The optical densitometric readings obtained from the control wells and subsequent dilutions 
were then converted to percentages. Then, control, 1/2,1/4, $1 / 8$ and $1 / 16$ dilutions were plotted as the abscissa of a linear regression graph with corresponding percentages of optical densitometric values as the ordinates. By using Instat Statistical Software, a linear regression line was fitted onto the converted values and the dilution on the abscissa that produced $50 \%$ cytotoxicity (Cytotoxic Dilution 50\%, abbreviated $\mathrm{CD}_{50}$ ) was determined by interpolation on the regression line. These $\mathrm{CD}_{50}$ values were used as an expression of the cytotoxicity potentials of the substances and they were used for comparison in accompaniment with corresponding correlation coefficient values $\left(\mathrm{r}^{2}\right)$. The effect of irrigation solutions was evaluated by comparing the mean optical density (OD) value of treated cells to the

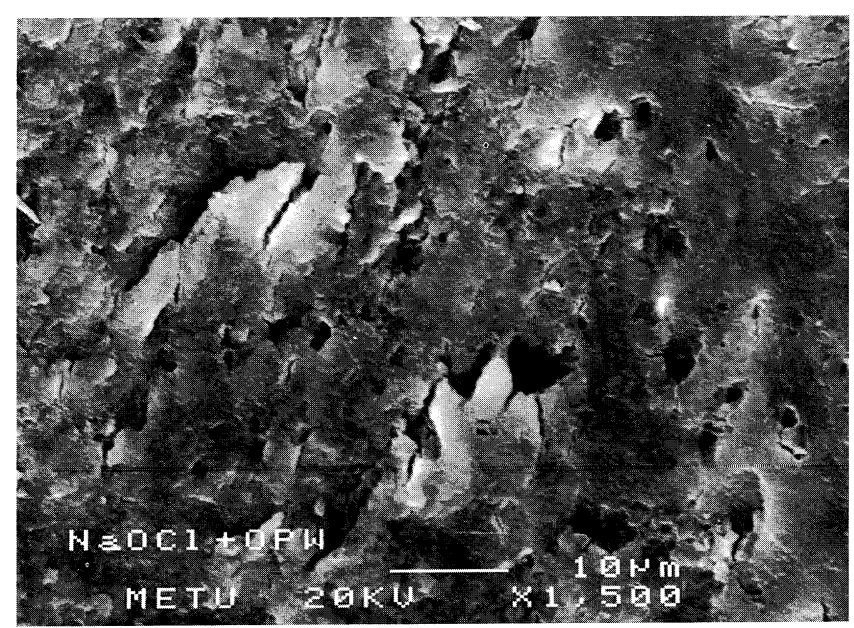

Fig. 1 Effects of $\mathrm{NaOCl}$ and OPW administration on the apical third of the root canal. An amorphous smear layer is present and most of the dentinal tubule openings are blocked by the smear layer $(\times 1500)$.

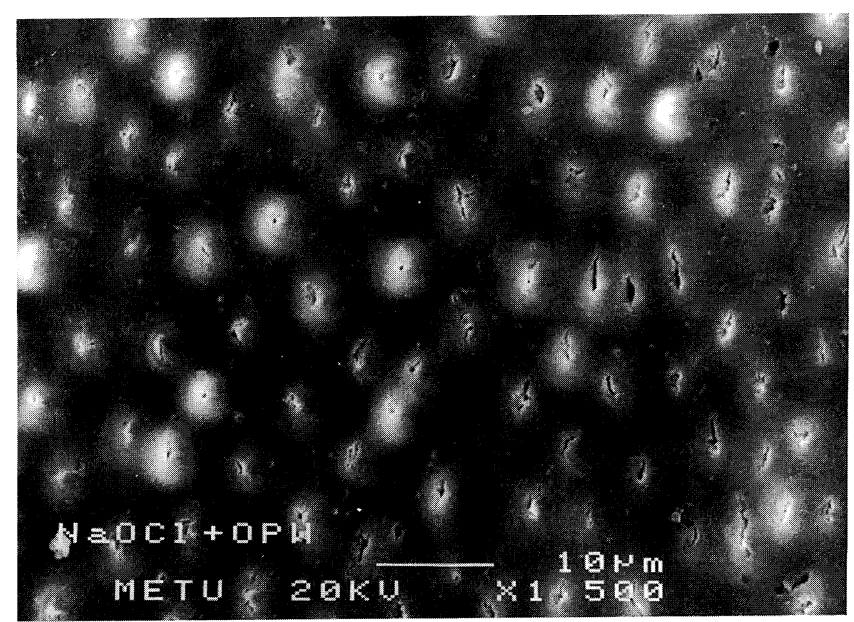

Fig. 2 The middle third of the root canal irrigated with $\mathrm{NaOCl}$ and OPW. A thin smear layer covers the intertubular surface and openings of the dentinal tubules $(\times 1500)$. mean OD of untreated control wells.

\section{Results}

\section{SEM examination}

Group 1: Specimens irrigated with $5 \% \mathrm{NaOCl}$, followed by OPW, showed a heavy smear layer in the apical third. Dentinal tubule openings were obscured by extensive debris (Fig. 1). The middle third of these specimens appeared to be relatively clean. Tubule outlines were hardly visible and all of the tubular apertures were plugged with the smear material (Fig. 2).

Group 2: Specimens irrigated during and after instrumentation with OPW, displayed similar findings with group 1 in the apical third. Smear plugs covered the apertures of

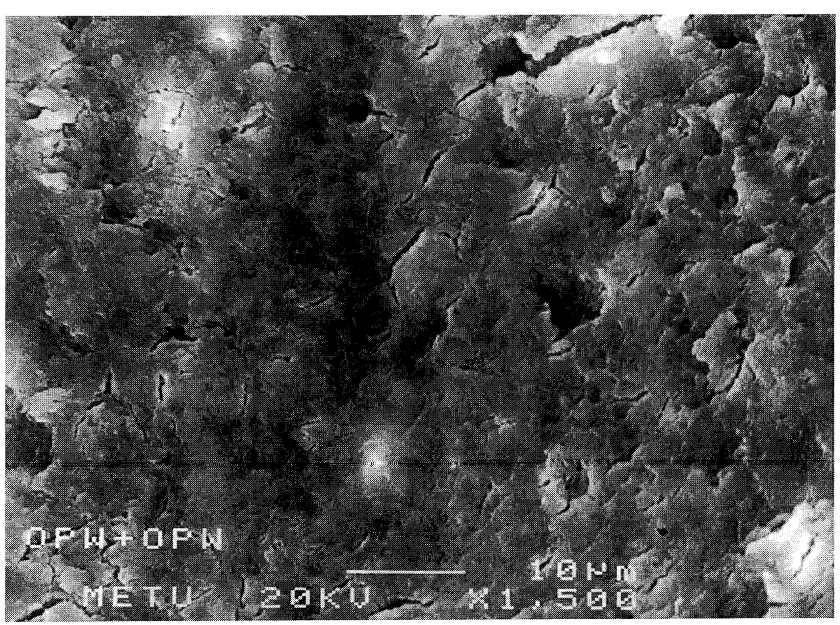

Fig. 3 Effects of OPW and OPW irrigation on the apical third of the root canal. Dentinal tubule openings are obscured by an adherent smear layer $(\times 1500)$.

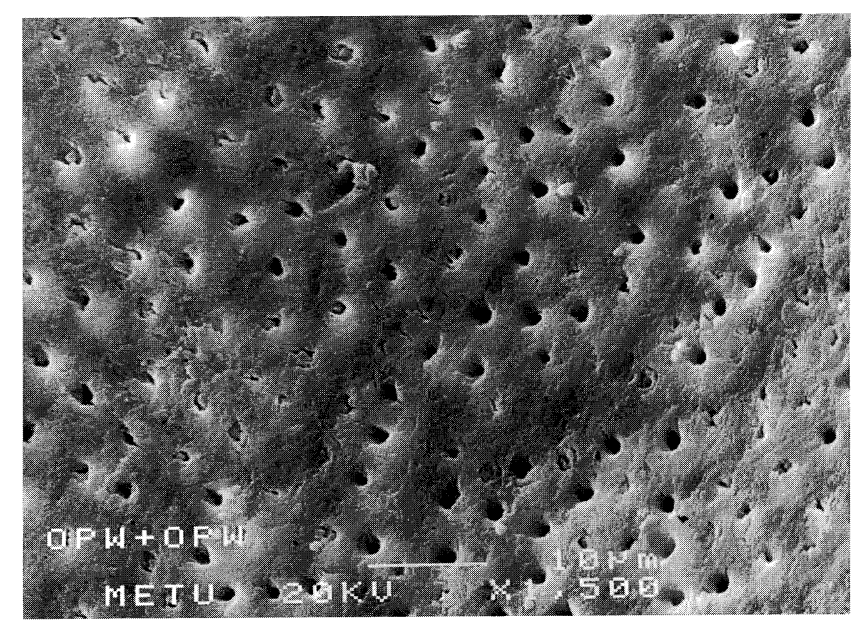

Fig. 4 Effects of OPW and OPW administration on the middle third of the root canal. The canal wall surface is almost free of smear layer. Most of the tubule openings are clearly visible, some tubular apertures are plugged with debris $(\times 1500)$. 


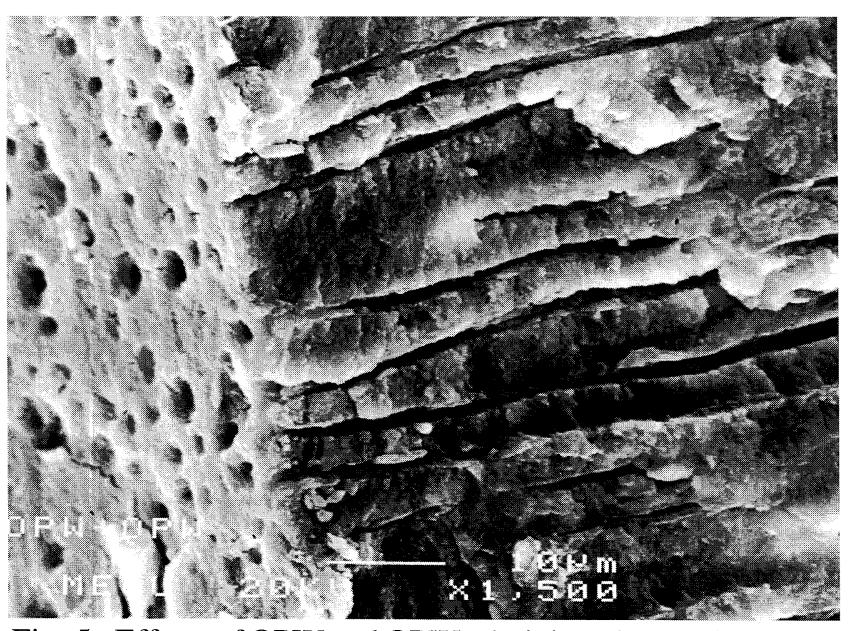

Fig. 5 Effects of OPW and OPW administration on the middle third of the root canal as shown from a longitudinal view. Few smear plugs are seen penetrating into the dentinal tubules $(\times 1500)$.

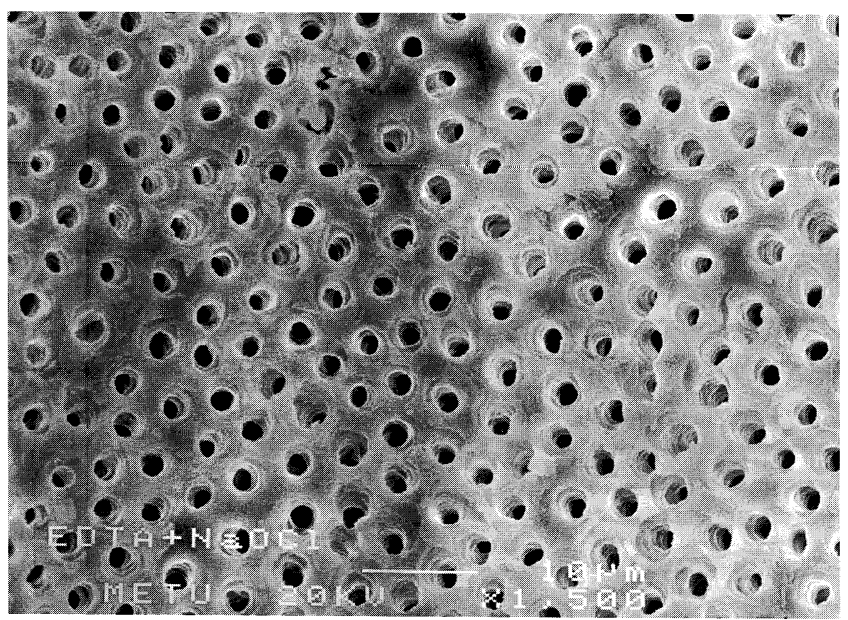

Fig. 6 Effects of EDTA on the middle third of the root canal. The smear layer is completely removed and the intertubular dentin is observed with some erosive effects $(\times 2000)$.

the dentinal tubules (Fig. 3). The smear layer was almost effectively removed, but a slight amount of debris was observed that obscured tubule orifices in the middle third (Fig. 4). In longitudinal sections, a slight penetration of plugs into the tubules was clearly observed in the same area (Fig. 5).

Group 3: Irrigation of the specimens with $\mathrm{NaOCl}$ followed by EDTA and $\mathrm{NaOCl}$ resulted in complete removal of the smear layer in the apical and middle third. In these specimens, enlargement of the dentinal tubule openings was observed (Fig. 6).

\section{Cytotoxicity assays with solutions}

The cytotoxicity of irrigation solutions OPW, EDTA and
$\mathrm{NaOCl}$ at different concentrations was assessed in $\mathrm{L} 929$ cells using the MTT assay. The results of the cytotoxicity experiments, which illustrate the percentage of OD values of irrigation solution-treated cells to the OD value of control cells, are presented in Table 1 and cytotoxic potentials of these irrigation solutions are given in Table 2. Although the diluted concentrations of OPW and $\mathrm{NaOCl}$ did not exert toxic effects, we observed $50 \%$ cell death in lower dilutions. $\mathrm{CD}_{50}$ values for $\mathrm{OPW}$ and $\mathrm{NaOCl}$ are $1 / 2$ and 1/3.7, respectively. EDTA was found to be very toxic at all dilutions tested.

\section{Discussion}

Successful root canal treatment depends on proper chemical and mechanical debridement of the root canal system. Since no single agent has been found to be sufficient for this purpose, various combination of irrigants have been studied (10-12,15).

In this study, we evaluated three different irrigation solutions (OPW, $\mathrm{NaOCl}$ and EDTA) in combination. OPW, which is strongly acidic with a $\mathrm{pH}$ of 2.5 , is produced by electrolysis of tap water containing a small quantity of $\mathrm{NaCl}$. We found that instrumentation of the root canal with 5\% $\mathrm{NaOCl}$ followed by OPW and OPW-OPW treatment failed to remove the smear layer in the apical third and left additional extensive debris at the dentinal openings. On the other hand, we also found that OPW, when used during and after instrumentation, removed the smear layer in the middle third more effectively than $\mathrm{NaOCl}$ followed by OPW (but the tubule openings were still clogged). However, Hata et al. (12) reported that OPW, when used during and after root canal instrumentation, resulted in the smear layer on the root canal surface not being observed and the tubular packing phenomenon not being observed in the tubules. This discordance may be due to the differences in technical manipulations. Hata et al. (12) also reported that OPW in combination with EDTA cleans the root canal surfaces retaining no smear layer. Our study showed that $\mathrm{NaOCl}$ followed by EDTA and $\mathrm{NaOCl}$ irrigation achieves complete smear layer removal on the apical and middle third of root canal, although erosive effects were observed at the tubular openings. EDTA is a strong chelator, exerting a demineralizing effect reacting with calcium ions in the hydroxyapatite crystals of dentin. However, the smear layer removing capability should be considered with its toxic and erosive effects. Ideally, an irrigation solution is expected to remove the smear layer with as low of a toxicity as possible. Normally, as the concentration of a solution is increased, unwanted cytotoxic effects are produced. OPW is accepted to be safe for patients to hold in the oral cavity, due to its ability to lose the high oxidation- 
reduction potential and low $\mathrm{pH}$ upon reacting to light and/or organic substances (12). Our results show that OPW has lower cytotoxicity than $\mathrm{NaOCl}$ and EDTA. In this study, we found that the cytotoxicity of EDTA was remarkable at any dilution as evaluated by MTT assay $(16,17)$. These findings are in agreement with Koulaouzidou et al. (7) who reported that at $17 \%, 15 \%$ and $1 \%$, EDTA demonstrated severe cytotoxicy in vitro. According to Segura et al. (18), the apical extrusion of EDTA not only causes a decalcificant action on periapical bone, but it also may have effects on neuroimmune regulation, even when the concentration of EDTA is very low. They also reported that leakage of EDTA to periapical tissues during root canal preparation may inhibit macrophage function and reduce periapical inflammatory reactions (19).

Our findings indicate that OPW has the lowest cytotoxicity, but could not completely remove the smear layer. For this reason, it can best be utilized in combination with a chelator substance which has better smear layer

Table 1 The percentage of OD values of irrigant-treated cells to the control cells

\begin{tabular}{llllll}
\hline & Control & $\mathbf{1 / 1 6}$ & $\mathbf{1 / 8}$ & $\mathbf{1 / 4}$ & $\mathbf{1 / 2}$ \\
\hline OPW & 100 & 97.72 & 88.40 & 75.81 & 48.42 \\
$\mathrm{NaOCl}$ & 100 & 54.27 & 51.16 & 44.59 & 37.45 \\
EDTA & 100 & 30.59 & 29.34 & 26.95 & 24.89
\end{tabular}

Table 2 Cytotoxic potentials of irrigation solutions on L929 cells

\begin{tabular}{lll}
\hline & CD $_{50}$ & $\mathbf{r}^{2}$ \\
\hline OPW & $1 / 2$ & 0.9944 \\
$\mathrm{NaOCl}$ & $1 / 3.7$ & 0.5351 \\
EDTA & $1 / 9.2$ & 0.3425 \\
\hline
\end{tabular}

$\mathrm{D}_{50}$ stands for cytotoxic dilution 50 ; for description see Materials and Methods section.

$\mathrm{r}^{2}$ : correlation coefficient.

removal characteristics. We believe that OPW may be considered as an alternative irrigation solution, however, finding the best combination needs further study. In addition, antimicrobial and tissue dissolution properties of OPW must be investigated.

\section{References}

1. West, J.D. and Roane, J.B. (1998) Cleaning and shaping the root canal system. In Pathways of the pulp. 7th ed., Cohen, S. and Burns, R.C. eds., Mosby, St. Louis, 206-208
2. Ingle, J.I., Bakland, L.K., Peters, D.L., Buchanan, L.S. and Mullaney, T.P. (1994) Endodontic cavity preparation. In Endodontics. 4th ed., Ingle, J.I.and Bakland, L.K. eds., Williams \& Wilkins, Baltimore, 181-182

3. Walton, R.E. and Rivera, E.M. (1996) Cleaning and shaping. In Principles and practice of endodontics. 2nd ed., Walton, R.E. and Torabinejad, M. eds., W.B. Saunders, Philadelphia, 212-214

4. Barnard, D., Davies, J. and Figdor, D. (1996) Susceptibility of Actinomyces isr aelii to antibiotics, sodium hypochlorite and calcium hydroxide. Int. Endod. J. 29, 320-326

5. Hand, R.E., Smith, M.L. and Harrison, J.W. (1978) Analysis of the effect of dilution on the necrotic tissue dissolution property of sodium hypochlorite. J. Endod. 4, 60-64

6. Pashley, E.L., Birdsong, N.L., Bowman, K. and Pashley, D.H. (1985) Cytotoxic effects of $\mathrm{NaOCl}$ on vital tissue. J. Endod. 11, 525-528

7. Koulaouzidou, E.A., Margelos, J., Beltes, P. and Kortsaris, A.H. (1999) Cytotoxic effects of different concentrations of neutral and alkaline EDTA solutions used as root canal irrigants. J. Endod. 25, 21-23

8. Yeşilsoy, C., Whitaker, E., Cleveland, D., Phillips, E. and Trope, M. (1995) Antimicrobial and toxic effects of established and potential root canal irrigants. J. Endod. 21, 513-515

9. Şen, B.H., Wesselink, P.R. and Türkün, M. (1995) The smear layer: a phenomenon in root canal therapy. Int. Endod. J. 28, 141-148

10. Yamada, R.S., Armas, A., Goldman, M. and Lin, P.S. (1983) A scanning electron microscopic comparison of a high volume final flush with several irrigating solutions: part 3. J. Endod. 9, 137-142

11. Baumgartner, J.C. and Mader, C.L. (1987) A scanning electron microscopic evaluation of four root canal irrigation regimens. J. Endod. 13, 147-157

12. Hata, G., Uemura, M., Weine, F.S. and Toda, T. (1996) Removal of smear layer in the root canal using oxidative potential water. J. Endod. 22, 643-645

13. Mosmann, T. (1983) Rapid colorimetric assay for cellular growth and survival: application to proliferation and cytotoxicity assays. J. Immunol. Methods 65, 55-63

14. Hansen, M.B., Nielsen, S.E. and Berg, K. (1989) Reexamination and further development of a precise and rapid dye method for measuring cell growth/cell kill. J. Immunol. Methods 119, 203-210

15. Berg, M.S., Jacobsen, E.L., BeGole, E.A. and 
Remeikis, N.A. (1986) A comparison of five irrigating solutions: a scanning electron microscopic study. J. Endod. 12, 192-197

16. Schweikl, H. and Schmalz, G. (1996) Toxicity parameters for cytotoxicity testing of dental materials in two different mammalian cell lines. Eur. J. Oral Sci. 104, 292-299

17. Telli, C., Serper, A., Dogan, A.L. and Guc, D. (1999) Evaluation of the cytotoxicity of calcium phosphate root canal sealers by MTT assay. J. Endod. 25, 811813
18. Segura, J.J., Calvo, J.R., Guerrero, J.M., Sampedro, C., Jimenez, A. and Llamas, R. (1996) The disodium salt of EDTA inhibits the binding of vasoactive intestinal peptide to macrophage membranes: endodontic implications. J. Endod. 22, 337-340

19. Segura, J.J., Calvo, J.R., Guerrero, J.M., JimmenezPlanas, A., Sampedro, C. and Llamas, R. (1997) EDTA inhibits in vitro substrate adherence capacity of macrophages: endodontic implications. J. Endod. 23, 205-208 